\title{
Specialized stroke nursing program using an inter-professional approach: A nurse-driven education initiative of one stroke hospital in Saudi Arabia
}

\author{
Elmer Catangui * \\ Nursing Services and Center of Nursing Education, King Abdulaziz Medical City, National Guard Health Affairs, Riyadh, Saudi \\ Arabia
}

Received: April 7, 2015

DOI: $10.5430 /$ jnep.v5n11p 81

\author{
Accepted: July 12, 2015 \\ Online Published: August 19, 2015 \\ URL: http://dx.doi.org/10.5430/jnep.v5n11p81
}

\begin{abstract}
The incidence of stroke is remarkably increasing in the Kingdom of Saudi Arabia. The integration of evidence-based practice is essential in provision of specialist stroke care to all stroke patients. The King Abdullaziz Medical City (KAMC) in Riyadh has reconfigured the stroke services by creating a novel stroke model where all suspected stroke patients are directly admitted to the high dependency stroke unit (HDSU) in order to provide an integrated and specialized care to the stroke population. Prior to the launch of the new stroke model, training was imperative for all nurses. The article will describe the development and evaluation of the specialized stroke nursing programme using an inter-professional learning approach.
\end{abstract}

Key Words: Stroke training, Stroke, Learning needs analysis, Inter-professional training, Multidisciplinary team

\section{INTRODUCTION}

"Stroke is becoming a rapidly increasing problem and an important cause of mortality and morbidity in Saudi Arabia. However, compared with the developed countries, research regarding the incidence, prevalence and their sociodemographic properties of stroke is still insufficient due to lack of appropriate studies being conducted in these specified areas". ${ }^{[1]}$ "Arab countries constitute populations with a similar lifestyle and diet that may influence stroke risk, type and survival after stroke, as well as other characteristics in comparison to Western and Oriental populations." ${ }^{[2]}$

King Abdulaziz Medical City has envisioned a new stroke model (see Figure 1) that all stroke patients are directly admitted to a highly specialist emergency unit where these patients will have a rapid access to a computerized tomography (CT) imaging. Eligible patients are treated with a thrombolysis or a clot busting therapy within 4.5 hours of stroke onset. The stroke patients regardless whether they are thrombolyzed or not should then be transferred to the high dependency stroke unit (HDSU) in order to receive integrated and specialized stroke care within 72 hours from highly trained nurses, doctors and the multidisciplinary team. A 72-hour provision of monitoring and continuous care is the most crucial stage of acute stroke management of stroke to prevent complications. After 72 hours to HDSU, the patients will then move to the acute stroke unit for ongoing rehabilitation with medical support. The new stroke model is aimed to reduce mortality rate of stroke, improve patients length of stay and enhance patients quality of life after stroke.

${ }^{*}$ Correspondence: Elmer Catangui; Email: elmer.catangui@ngha.med.sa; Address: Center of Nursing Education, Acute stroke unit, King Abdulaziz Medical City, Riyadh, Saudi Arabia. 
In preparation for the launching of the new stroke model, a high priority to ensure the staff received specialist training in order to provide the highest possible care for this patient population was therefore needed.

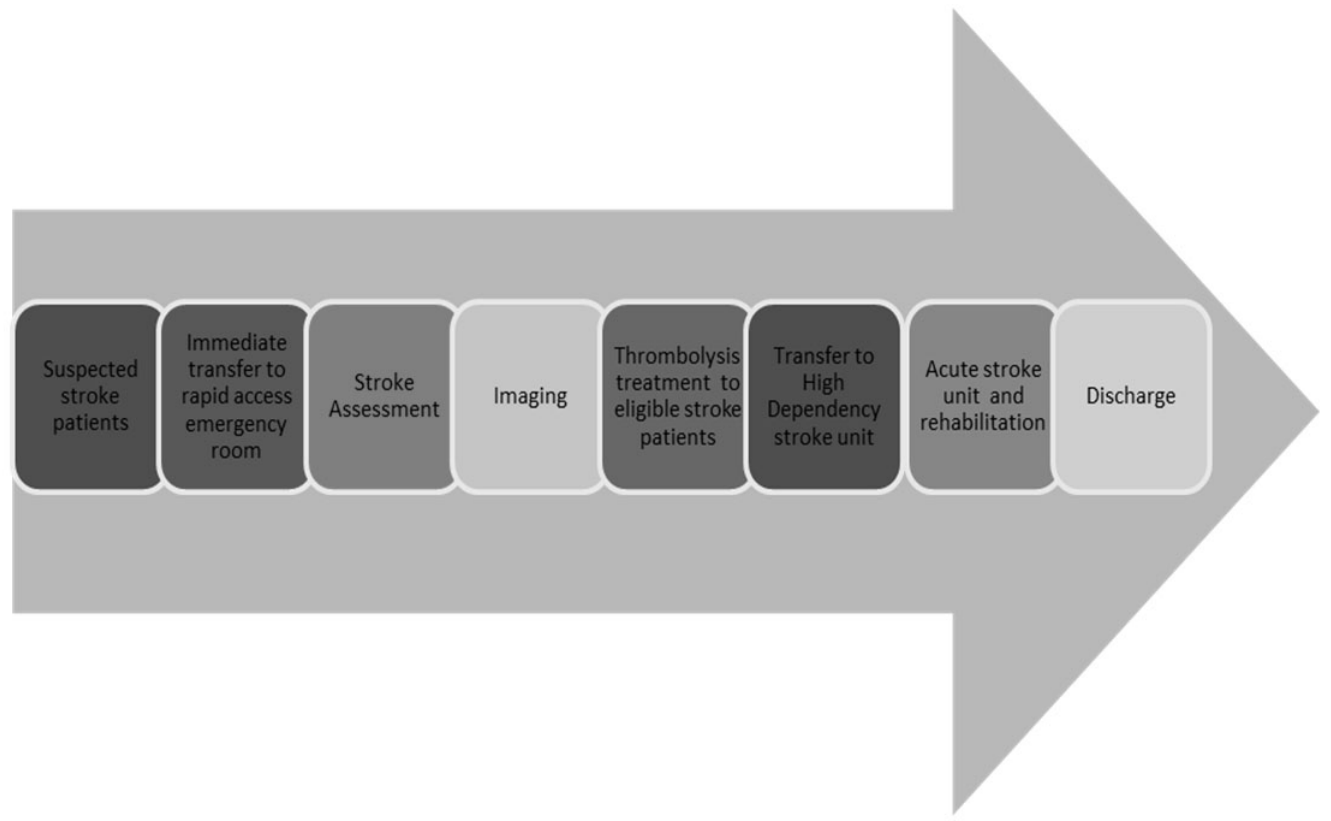

Figure 1. KAMC novel stroke model

\section{Literature review}

The context of inter-professional education (IPE) is thought to prepare health care professionals for successful collaborative practice. ${ }^{[3]}$ The concept of inter-professional education is supported in the literature, however, little is known in the development and implementation of stroke training program optimizing the inter-professional learning approach and organizing the program structure, stages and process.

An annual comprehensive stroke program was developed and implemented targeting nursing staff both medical and surgical in collaboration with the stakeholders (therapists, directors, and multidisciplinary team) ${ }^{[4]}$ It concluded that collaboration among all stakeholders was critical in the design of a program to meet the educational needs and to provide quality care for stroke patients. ${ }^{[4]}$

In the UK, an in-service interdisciplinary training program was implemented in response to an identified need for staff education in stroke care. The program is designed however for allied health care professionals focusing on the assessment and management of psychological and communication problems after stroke but stroke care pathway related topics from acute phase of stroke management and treatment were not incorporated. The use of an interdisciplinary focus in the stroke care program appears to have benefits for more integrated team working and holistic management of patients. ${ }^{[5]}$

A structured and collaborative training for stroke nursing focussing on the positioning and mobility as key concepts was developed and illuminated the 4 sequential stages of developing a program. ${ }^{[6]}$ These stages include interview process among potential participants, analysis of the assessment interview, core planning group and evaluation of the program based on patients outcome. Overall, it appeared that the use of informed and structured content of the course and interprofessional working promotes a collaborative learning. ${ }^{[6]}$

With the introduction of the hyperacute stroke care in London, an interdisciplinary stroke program to develop nurses' competencies was launched. ${ }^{[7]}$ The participation of the multidisciplinary team in the core planning had a tremendous impact in providing evidence-based practice in stroke care. ${ }^{[7]}$ The training contents embraced all important key concepts of stroke care, however, the sequential stages of the planning process were not fully discussed in detail.

An inter-professional pilot training course aimed at prelicensure practitioners working with post-stroke patients in community-based settings was introduced in core curriculum development. ${ }^{[8]}$ It optimizes various teaching-learning strategies to facilitate interactive sessions. The findings indicate students' knowledge, skills and self-confidence in delivering effective post-stroke care increased following the training. ${ }^{[8]}$ 
Overall, the literatures describe the scope of contents and limitations in the development of a stroke training program for nurses.

The aim of the article is to lay out the development and implementation of a specialized stroke nursing program (SSNP) as a continuing education initiative using inter-professional learning approach. It will describe the sequential planning stages, the processes, and the timeline of its development. It will define the contents of the SSNP. It will also describe the feedback from participants attending the SSNP.

\section{MethodS}

A core faculty group from professionals with expertise in stroke care developed a SSNP aimed at all nurses. The goal is for specialists from all members of the stroke team to teach acute care nurses involved in stroke patient care using a framework of inter-professional learning approach.

The core faculty group in stroke with joint effort of the Center of Nursing Education has set action planning as necessary for the development and implementation stages of the SSNP. The sequential planning stages and its time line for implementation (see Figure 2) describe the development of the SSNP.

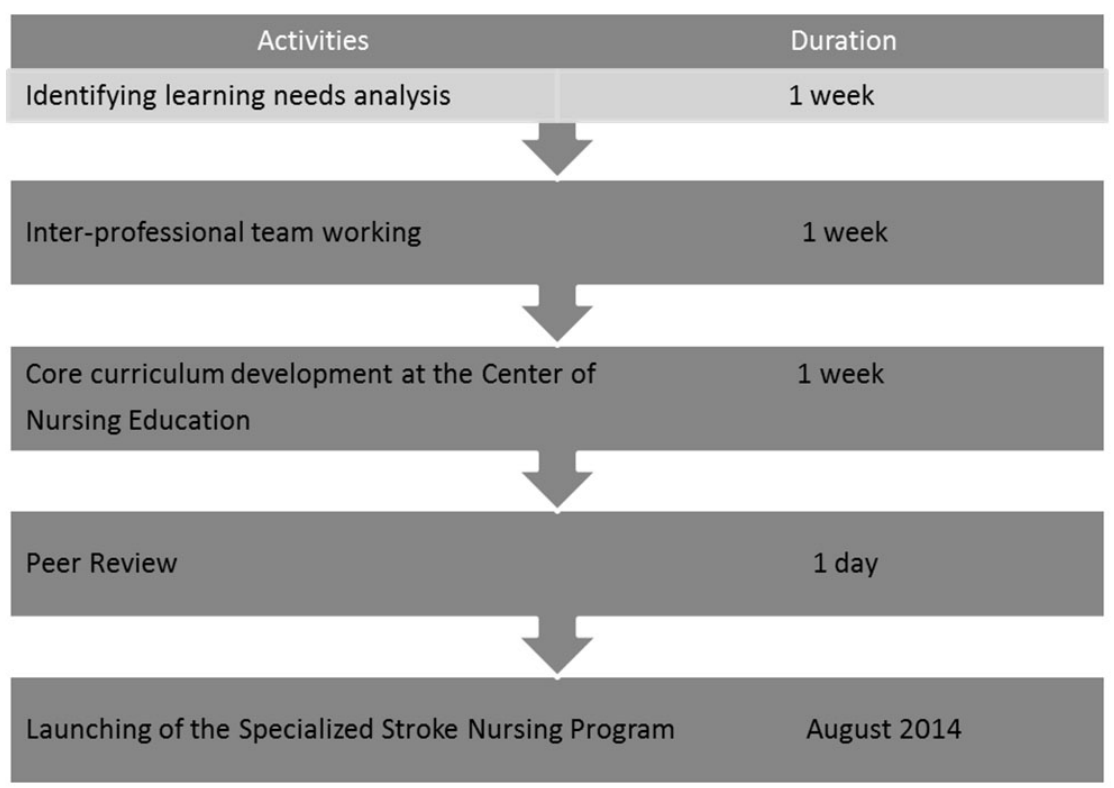

Figure 2. Sequential planning stages

Feedback evaluation was designed to identify the strengths and improvement areas of the program. After each run of the SSNP, evaluation feedback was given to participants. The data were analysed based on program evaluation from participants.

\section{Stage 1: Learning Needs Analysis (LNA)}

A learning needs analysis as a process of identifying specific stroke topics was conducted among 24 nurses from acute stroke unit. A questionnaire checklist was sent to them and retrieved within 1 week. The analysis shows that topics of great interest to the nursing team are highlighted in Figure 3.

The data imply that the use of an inter-professional learning approach is needed in order to capture all the key concepts of stroke care particularly inputs from therapists such as the dietician, speech and language pathologist (therapists), specialist nurses, and physiotherapists.

\section{Stage 2: Inter-professional team working}

A core of faculty consisting of clinical resource nurses (CRNs), nurse specialists and therapists (speech language pathologists, dietician and physiotherapists) was organized and developed and aimed to discuss the development of the SSNP as a team. The activities included setting session objectives, discussion of key concepts incorporated in the training, organizing training schedules, preparing training materials and finalizing the course contents, formulating competency checklists for nurses and evaluation. This faculty will also serve as speakers in the actual training. A key constituent of a well-organized stroke care is team functioning among members of the inter-professional team. ${ }^{[9]}$ An inter-professional team work requires individual's expertise, values, perception, structure, team engagement and process 
whilst maintaining professional contract within the team that each member contribution to patient care is appreciated. ${ }^{[10,11]}$ It is a collaborative relationship that exhibits a blending of professional cultures and it can be achieved through shar- ing skills, knowledge and changing attitudes to ameliorate the quality of patient care. ${ }^{[12-14]}$ Effective communication is vital to understand the roles and responsibilities of each member of the team. ${ }^{[15]}$

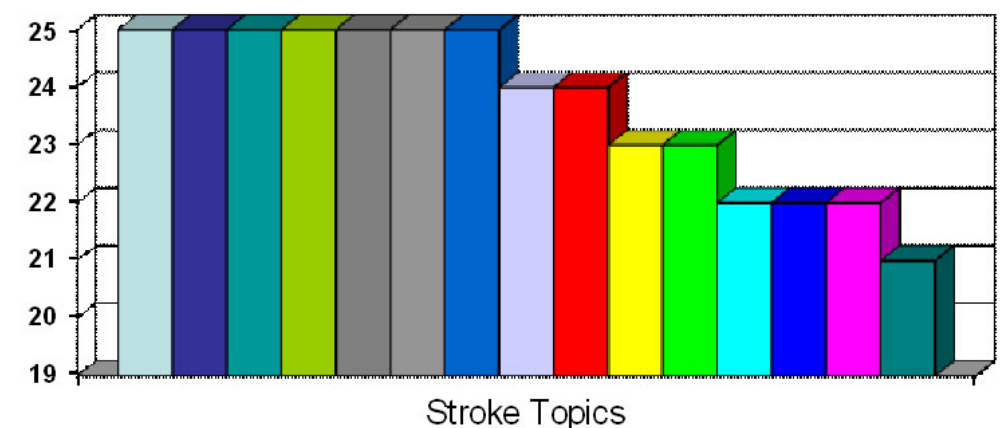

\begin{tabular}{|c|c|}
\hline \multicolumn{2}{|c|}{ 口Brain anatony and Overview of stroke $\mathbf{a N u r s i n g ~ A s s e s s m e n t ~ o f ~ s t r o k ~}$} \\
\hline 口Thrombolysis treatment for stroke & 口Imaging in stroke \\
\hline 口Stroke medications & 口Stroke complications \\
\hline 口Continence after stroke & 口Swallowing screening \\
\hline \multicolumn{2}{|c|}{$\square$ Dealing with patients having dysphasia Incidence of stroke in saudi } \\
\hline$\square$ Positioning & 口Nutrition after stroke \\
\hline Diabetes and stroke & 口Glasgow coma scale \\
\hline 口Stroke investigations & \\
\hline
\end{tabular}

Figure 3. LNA results $(\mathrm{n}=25)$

Stage 3: Collaboration to the nursing services' center of nursing education

The KAMC- (Riyadh) Nursing Services' Center of Nursing Education (NS-CNE) was collaborated to evaluate the quality of training program from the preparation, implementation and evaluation of the course. A subsequent meeting was held to raise important challenges in training approaches such as incorporating interactive case scenarios that include simulation and clinical practice session, group quiz and audiovisual presentation that make learning fun, and clinical competency achievement that reinforces theoretical knowledge. The overall aims of the SSNP were to enhance nurses' knowledge and skill in stroke care, intensify nursing skills on rapid assessment of stroke patients and reinforce evidence-based approaches in comprehensive nursing of stroke patients and their families.

\section{Program framework}

The SSNP is a two day training program which encapsulates two curriculum frameworks: overview of stroke / team working and specialized stroke nursing care (see Table 1). Day 1 explores the key concepts on stroke, its causes, prevention, investigations, assessment and treatment options. It also highlights the roles of each member of the stroke multidisciplinary team. On the other hand, day 2 is central to the specialized stroke nursing care for stroke which covers all topics pertaining to the monitoring role of a nurse on early detection and prevention of complications during acute phase of stroke.

The SSNP has been accredited by the NS-CNE using a curriculum framework and has been awarded 14 contact hours from Californian Board of Registered Nurses (CBRN).

A short session on effective presentation skills was given among the members of the SSNP faculty to enhance their impact in delivering their modules within a classroom or a clinical environment.

\section{Stage 4: Peer review}

A pilot run of the SSNP was held among nursing educators in August 2014. It aimed to review and address critical issues on training contents, process and structure of the program.

\section{Stage 5: Training implementation}

The selection of target participants were initially attended by group of nursing educators, then unit nurse managers, followed by CRNs, and clinical nurse coordinators and lastly group from all nurses who are taking care of patients with stroke. To date, the SSNP runs every Monday and Tuesday. Each unit manager is responsible to send their list of nurses and notify the nursing education through organized booking process. 
Table 1. SSNP structured training contents

\begin{tabular}{|c|c|c|}
\hline \multirow{11}{*}{$\begin{array}{l}\text { Day } 1 \text { Conceptual framework: } \\
\text { Overview of stroke and team } \\
\text { working }\end{array}$} & \multicolumn{2}{|c|}{ Topics } \\
\hline & - & What acute nurses should know about stroke? \\
\hline & - & Stroke in Saudi: Perceptions, social and cultural aspects of caring for patients with stroke \\
\hline & - & Nursing assessment of stroke patients \\
\hline & - & The use of the Glasgow coma scale in monitoring neurological status \\
\hline & - & Caring for stroke patients with swallowing difficulty: collaboration with Speech \& \\
\hline & & Swallowing Pathologist \\
\hline & & Nutritional management of acute stroke patients: collaboration with Clinical Dietician \\
\hline & & Caring for stroke patients with communication difficulty: collaboration with Speech \& \\
\hline & & Swallowing Pathologist \\
\hline & - & Positioning/Transferring and providing shoulder care to stroke patients \\
\hline \multirow{11}{*}{$\begin{array}{l}\text { Day } 2 \text { Conceptual framework: } \\
\text { Specialized stroke nursing care }\end{array}$} & \multicolumn{2}{|r|}{ Topics } \\
\hline & 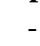 & Thrombolysis treatment - the role of the nurse \\
\hline & & The role of the nurse in early identification of deterioration in stroke patients and the \\
\hline & & physiological monitoring in stroke \\
\hline & & The nursing role in safe administration of stroke medications \\
\hline & & Continence after stroke \\
\hline & & (Bladder and bowel nursing management) \\
\hline & - & The use of evaluation tools in assessing outcomes \\
\hline & & Nursing Essentials in stroke patient care \\
\hline & & Stroke nursing competencies \\
\hline & & Unit Clinical Leadership and nursing roles in optimizing stroke care \\
\hline
\end{tabular}

\section{RESULTS, ANALYSIS AND DISCUSSION}

The SSNP was up and continuously running since August 2014 to date. It has been attended 600 participants (see Table 2). Using the evaluation form given to participants each session, the frequencies of response to each indicator (strongly agree, agree or disagree) were presented into table (see Table $3)$. The participants' comments of the session were also collated and interpreted using a thematic analysis (see Figure
4).

The participants of the SSNP are mostly nurses from emergency and acute medical units $(86.5 \%)$ (see Table 2). The selection of participants based on position groups (see Table 2) helps the SSNP faculty to have specific learning focus of each target cohort. Each cohort provides a clear understanding of their role in optimizing stroke care and will envisage the relevance of the program to the clinical practice.

Table 2. Participants

\begin{tabular}{ll}
\hline Group & Total \\
\hline Nursing educators/directors of nursing and nurse specialist & $15(2.5 \%)$ \\
Nurse managers & $21(3.5)$ \\
Clinical resource nurses & $22(3.6 \%)$ \\
Clinical nurse coordinators & $23(3.8 \%)$ \\
Nurse from acute medical units, stroke and emergency nurses & $519(86.5 \%)$ \\
Total & $\mathbf{6 0 0}$ participants \\
\hline
\end{tabular}

Using the feedback evaluation (see Table 3), the participants strongly agree that the SSNP provides an opportunity to learn new skills in stroke management and these gained skills were clinically essential to patient care. They were keen to apply them into their practice. The participants also felt that interprofessional speakers delivered their topics proficiently and responded well to participants' questions.

The participants appreciate the use of clinical practice ses- sions (CPS) in developing their competence in stroke assessments such as FAST (Face, Arm, Speech and Time as a triage tool for suspected stroke), Glasgow coma scale, and basic neurological examination. It also provided them with a platform to identify their strengths and improvement areas of each skill. The CPSs on practical tips in positioning with stroke patients gave participants an overview of early prevention of stroke complications (hospital acquired pressure ulcer, shoulder subluxation or pneumonia). The SSNP promotes an 
opportunity for inter-professional discussion of patient case scenario sessions and role-play. The CPSs provide a safe environment away from the clinical area in which to discuss professional practices and acquire evidence-based practices.

As reflected in Figure 4, some participants view SSNP as a learning opportunity to expedite their role as a nurse in triage, assessment, care and evaluation of stroke patients. The SSNP gives them a prospect that gaining knowledge on stroke does not only apply at work but also in day to day life especially the early recognition of stroke symptoms and its prevention.

Table 3. SSNP training evaluation

\begin{tabular}{|c|c|c|c|c|}
\hline n-600 participants & $\begin{array}{l}\text { Strongly } \\
\text { Agree }\end{array}$ & Agree & Disagree & $\begin{array}{l}\text { Not Applicable } \\
\text { or No Comment }\end{array}$ \\
\hline The program met the learning outcomes as stated in the schedule. & 554 & 46 & 0 & 0 \\
\hline The program information is applicable to my nursing practice. & 578 & 22 & 0 & 0 \\
\hline The information was presented at a level which challenged me. & 542 & 58 & 0 & 0 \\
\hline I have gained new information from this program. & 571 & 29 & 0 & 0 \\
\hline I intend to apply the information I gained from this program to my nursing practice. & 570 & 30 & 0 & 0 \\
\hline The session facilitators were able to explain concepts in clear $\&$ logical way. & 564 & 36 & 0 & 0 \\
\hline The session facilitators were able to answer my questions clearly. & 577 & 23 & 0 & 0 \\
\hline The teaching methods used were appropriate. & 572 & 28 & 0 & 0 \\
\hline The clinical practice sessions were helpful. & 578 & 22 & 0 & 0 \\
\hline I felt comfortable participating in the clinical practice sessions & 543 & 57 & 0 & 0 \\
\hline The clinical scenario discussions helped me apply the principles covered. & 532 & 68 & 0 & 0 \\
\hline I felt comfortable participating in the clinical scenario discussions. & 520 & 80 & 0 & 0 \\
\hline The clinical scenarios used were relevant to my clinical practice. & 534 & 66 & 0 & 0 \\
\hline The audiovisual equipment was efficient and effective. & 567 & 33 & & \\
\hline The handouts were useful. & 502 & 98 & 0 & 0 \\
\hline
\end{tabular}

The participants also felt that all topics were clinically relevant in provision of total nursing care to all patients. They easily grasped new skills and ideas because they viewed the SSNP sessions were designed to address their learning needs.

The participants expressed that the use of expert speakers coming from a multidisciplinary stroke team helped them to understand and clarify their roles as therapists and nurse specialist in provision of stroke care and shared their level of expertise to participants.

The participants perceived SSNP as an innovative way of learning new concepts of stroke care. The use of various teaching learning approaches/strategies from this training such as lecture, audio-visual presentation, practical tips, patient case scenarios, role playing, and simulation supported their learning experiences and sustained bedside nursing care. The use of multiple learning activities and integrating patient scenarios in educational exploration is central to advancing evidence-based practice. ${ }^{[8]}$

On the other hand, the participants have suggested the usefulness of having an electronic stroke learning tool where they could have an access of the slides presentation, published articles and stroke updates.
In summary, in order to achieve inter-professional teamwork, learning from each other is vital to understand the multidisciplinary team and share each others' expertise. Learning together enhances collaboration within inter-professional team. To be an effective collaborative healthcare professional, a core competency framework which consists of interprofessional indicators will help practitioners to enable them to work collaboratively. ${ }^{[16]}$

The development of a SSNP (see Table 1) is an excellent example of a nurse-driven education initiative that promotes inter-professional learning toward improving patient outcomes. An inter-professional education occurs when two or more professions learn with, from and about each other to improve collaboration and the quality of care. ${ }^{[1]}$ An inter-professional working requires a positive team working where members have personal qualities, commitment and opportunity to stimulate creative thinking. ${ }^{[18]}$

The philosophy of inter-professional learning approach helps to achieve the benefits of collaborative learning and an understanding of the differences among professional groups. ${ }^{[7]}$ Working in a stroke unit requires collaborative synergy among the members of the multidisciplinary team. Team 
work should be regarded a cornerstone in the provision of the best possible care for stroke patients. It should be considered as an important core competency where healthcare providers including nurses must understand the principles of team dynamics and group processes to improve effective inter-professional team collaboration. ${ }^{[16]}$ Improvement in the inter-professional teamwork and effective communication has been proven to diminish institutionalisation and mortality associated with stroke. ${ }^{[15,19]}$

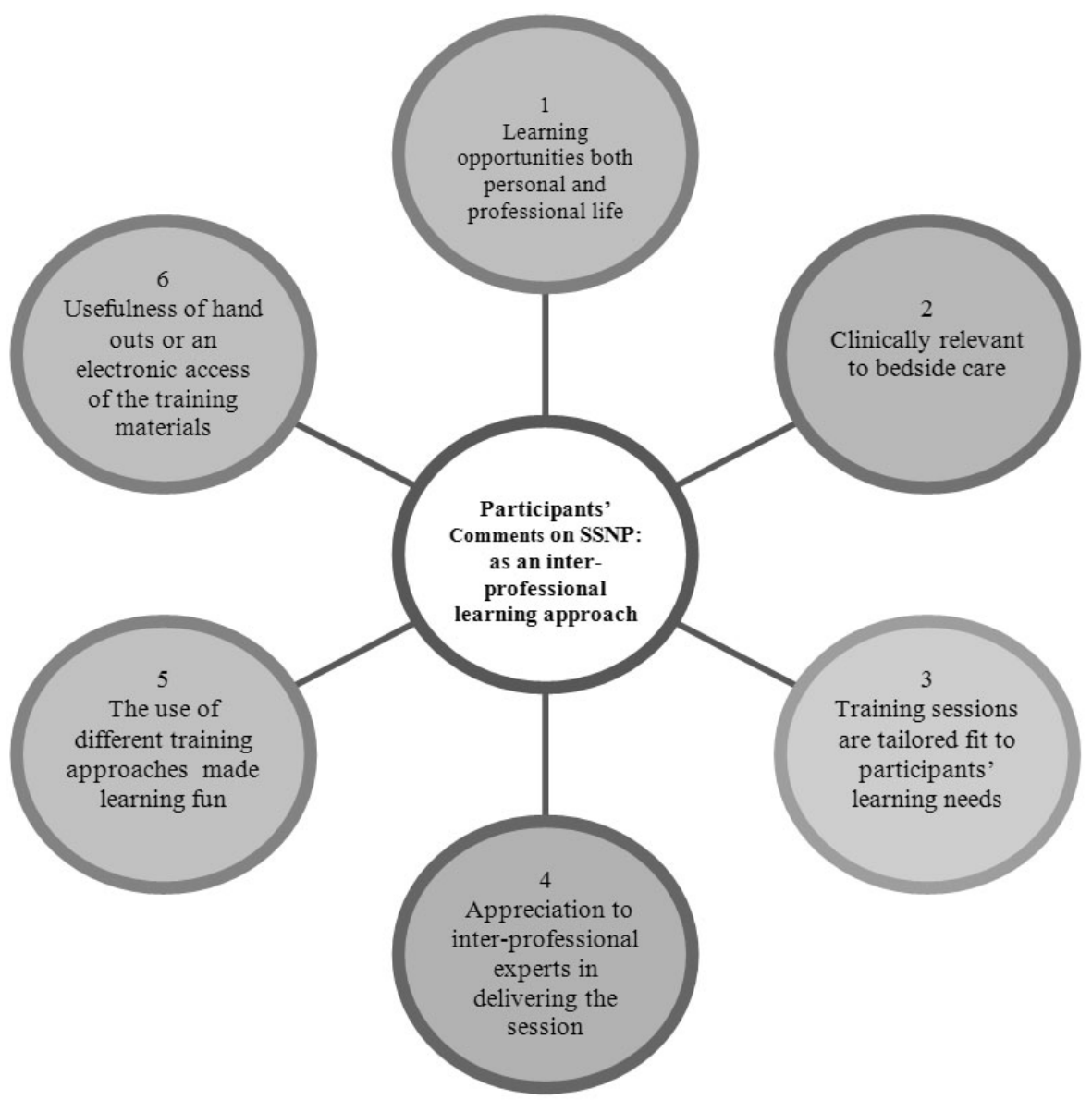

Figure 4. Participants' comments

\subsection{Key learning points}

(1) The use of inter-professional learning approach offers a comprehensive stroke care training for nurses addressing their learning needs. The support of expert professionals from the multidisciplinary team has a huge contribution to provide clinical information, theoretical and practical session on stroke.

(2) Working as a team is a key ingredient in the development of specialized stroke nursing program.

(3) Continuous training and the development of competencies among is critical ingredient in the provision of safe and integrated care to stroke patients.

\section{Conclusion}

The development of the SSNP at the King Abdulaziz Medical City (Riyadh) using an inter-professional learning approach appears to be an effective way of learning collaboratively. The positive synergy of expert professionals in delivering the stroke sessions have a huge contribution to envisage that evidence-based practice and key concepts of stroke are relevant to participants' clinical nursing practice. The SSNP is constantly evolving in response to the feedback from participants. It is an end result of a highly committed and dedicated inter-professional team to achieve the highest possible standards of care and to deliver an integrated and specialist care to our stroke care recipients our patients.

\section{ACKNOWLEDGements}

The author would like to extend his sincerest thanks to the stroke multidisciplinary team, Center of Nursing Education and the Nursing Services who were involved in the planning and implementation of the SSNP. 


\section{CONFlicts OF InTEREST Disclosure}

The abstract was accepted and published by the European Stroke Conference (Austria, 2015), Patient Safety Forum, KAMC- Riyadh, Journal of Infection and Public Health
(2015), Health Sciences in Qatar: Teaching, Learning \& Inter-Professionalism, Teaching and Learning Conference 2015 University of Calgary Qatar (2015), 2nd UAE Clinical Simulation Conference in Dubai (2014).

\section{REFERENCES}

[1] Robert AA, Zamzami MM. Stroke in Saudi: A review of the recent literature. The Pan African Medical Journal. 2014; 17 14. PMid:24932325 http://dx.doi.org/10.11604/pamj . 201 4.17.14.3015

[2] Benamer HT, Grosset D. Stroke in Arab countries: a systematic literature review. J ournal of The Neurological Sciences. 2009; 284(1-2): 18-23. PMid:19428027 http://dx.doi.org/10.1016/j.jns.2 009.04 .029

[3] Oates M, Davidson M. A critical appraisal of instruments to measure outcomes of interprofessional education. Medical Education. 2015; 49(4): 386-98. PMid:25800299 http://dx.doi .org/10.1111/m edu. 12681

[4] Niemi J, McErlane K, Tillette N. Collaboration and Implementation Of an Annual Comprehensive Stroke Education Program. Med Surg Nursing. 2013; 22(5): 331-334. PMid:24358577

[5] Ross S, Barton J, Read J. Staff in-service training onpost-stroke psychological and communication issues. International Journal of Therapy and Rehabilitation. 2009; 16(6): 342-348. http://dx.doi .org/10.12968/ijtr.2009.16.6.42437

[6] Dowswell G, Bagley P, Forster A, et al. The development of a collaborative stroke training programme for nurses. Journal of Clinical Nursing. 1999; 8: 743-752. PMid:10827621 http://dx.doi.org $/ 10.1046 / j .1365-2702.1999 .00310 . x$

[7] Catangui E, Slark J. The development and evaluation of interdisciplinary training program for stroke. British Journal of Neuroscience Nursing. 2012; 8(1): 8-11. http://dx.doi.org/10.12968/bjnn .2012 .8 .1 .8

[8] Olaisen R, Mariscal-Hergert C, Shaw A, et al. Evaluation of an interprofessional educational curriculum pilot course for practitioners working with post-stroke patients. Journal of Interprofessional Care. 2013; 28(2): 160-162. PMid:24195682 http://dx.doi.org/10. 3109/13561820.2013.847406

[9] Strasser D, Falconer J, Herrin J, et al. Team functioning and patient outcomes in stroke rehabilitation. Archives of Physical Medicine and Rehabilitation. 2005; 86(3): 403-409. PMid:15759219 http: //dx.doi.org/10.1016/j.apmr.2004.04.046

[10] Reeves S, Zwarenstein RS, Goldman J, et al. Interprofessional education: effects on professional practice and health care outcomes (update). The Cochrane Cochrane Database Syst Rev. 2013. PMid:23543515 http://dx.doi.org/10.1002/1465185 8.CD002213.pub3

[11] Reeves S, Zwarenstein RS, Goldman J, et al. Interprofessional education: effects on professional practice and health care outcomes (review). The Cochrane Collaboration John Wiley \& Sons, Ltd; 2008.

[12] Rao R. Dignity and impudence: how should medical students acquire and practice clinical skills for use with older people? Med Educ. 2003; 37: 190-1. http://dx.doi.org/10.1046/j.1365-2923. 2003.01426.x

[13] Morrison S. Working together: why bother with collaboration? Work Bas Learn Prim Care. 2007; 5: 65-70.

[14] Bridges D, Davidson R, Odegard PS, et al. Interprofessional collaboration: three best practice models of inter-professional education. 2011 Apr 8.

[15] Selby JP, Fulford-Smith L, King A, et al. Piloting the use of an interprofessional stroke care learning package created by and for students. Journal of Interprofessional Care. 2011; 25: 294295. PMid:21425913 http://dx.doi .org/10.3109/13561820. 2011.552814

[16] Bainbridge L, Nasmith L, Orchard C, et al. Competencies for interprofessional collaboration. Journal of Physical Therapy Education. 2010; 24(1): 6-11.

[17] Centre for the Advancement Of Interprofessional Education (CAIPE). Defining IPE. 2002

[18] Molyneaux J. Interprofessional teamworking: what makes teams work well? Journal of Interprofessional Care. 2001; 15(1): 29-35. http://dx.doi.org/10.1080/13561820020022855

[19] Langhorne P, Duncan P. Does the organization of postacute stroke care really matter? Stroke. 2001; 32: 268-274. PMid:11136947 http://dx.doi.org/10.1161/01.STR.32.1.268 